\title{
Masculinity and Class in the Context of Dirty Work
}

\begin{abstract}
Through an ethnographic study of 'dirty work' (refuse collection and street cleaning), this article explores how masculinity and class intersect - how, in a mutually constitutive sense, they produce attitudes and practices, strengths and vulnerabilities, which are shaped by shifting relations of privilege and power. We find resistance to class subordination through adherence to traditional forms of masculinity and through esteem-enhancing social comparison (e.g. with women; with migrant workers). Men also mobilised powerful nostalgic themes around the loss of traditional jobs as well as trade union power. We argue that displays of masculine resilience in the face of devaluation are less indicative of a culture of masculine dominance but more an expression of vulnerability and social dislocation, serving both as a source of resistance whilst simultaneously reinforcing anchors of social disadvantage that characterise forms of dirty work. We suggest that combining social comparison with intersectionality can potentially highlight how categories of difference are strategically deployed in response to varied and unequally valued social positionalities.
\end{abstract}

Key words: masculinity, class, dirty work, gender practice 
Masculinity and Class

\section{Introduction}

Research on gender has traditionally been oriented towards the experiences of women, with men often seen as 'invisible gendered subjects' and so peripheral to analysis (Whitehead, 2004). More recently, gender research has focused on men as men (Collinson and Hearn, 1994): as integral to understandings of gendered power. However, as Brod and Kaufman (2004) argue, men are not always bearers of privilege and entitlement in organizations. Drawing on an ethnographic study of 'dirty work' -jobs or roles that are seen as disgusting or degrading (Hughes, 1952; Ashforth and Kreiner, 1999) - we explore the experiences of men in 'low level' occupations (specifically refuse collection and street cleaning) where gendered privilege from masculinity can be undermined by class and occupation and where labour market changes (e.g. deregulation; contracting out) have led to greater insecurity and feelings of vulnerability (Atkinson et al, 2012). Thus, we focus on how masculinity is practised in a context where class and low status work intersect with gender in relation to how such work is encountered and experienced. Our data additionally points to ethnicity through concepts of 'foreignness' as a further source of difference. We demonstrate the significance of displays of traditional masculinity in this context, of feelings of social dislocation that are partly ameliorated - but not fully resolved -through social comparison with (devalued) others and through attachment to a preferred past, as strategies of enhancing self-esteem.

There have been an increasing number of studies that address the issue of intersectionality, exploring how privilege and inequality are not reducible to only one axis of difference (Browne \& Misra, 2003; McCall, 2005). Researchers have also examined how gender plays out in conjunction with other categories, principally nationality, race, ethnicity and class (McCall, 2001; Adib et al, 2003). For example, by looking at the complex relationship of gender, sexuality and race, Kaufman (1999) has shown how men are not always the bearers of privilege and how their experiences in organizations attest to an ambivalent set of power relations based on multiple categories of difference. In her work on rethinking intersectionality, Nash (2008) 
Masculinity and Class

emphasizes close connections between privilege and subordination and how understanding these connections might offer new ways of understanding both oppression and domination. Following in this tradition, the ethnographic study of 'dirty work' presented here examines the challenges faced by men involved in 'low level' occupations and explores their investment in particular practices which reside at some of these intersections.

In focusing on men doing dirty work, our paper seeks to reinvigorate an interest in class as a category that is integral to understandings of gendered (dis)advantage - through the diverse ways in which class 'shapes and goes on shaping the individuals we are and the individuals we become' (Reay, 1998: 259). While early work placed class very much at the centre of analysis in charting the experiences of working class men (e.g. Willis, 1977; Tolson, 1977; Sennett and Cobb, 1972), issues of class have since been 'retired' in much of organization and gender based research (Skeggs, 1997; 2004; McDowell, 2003). There has accordingly been limited recent empirical work on the experiences of less skilled men as a classed as well as gendered category (Gregg and Wadsworth, 2003). This is an important gap given the reduced availability of traditionally 'masculine' work and the increasing marginalisation of less skilled men within a labour market that gives priority to 'clean' value-adding work (Bolton and Houlihan, 2009; Gregg and Wadsworth, 1998). In addition, jobs deemed suitable and accessible for less skilled workers frequently involve a dangerous or dirty environment, close supervision, and limited opportunities for upward mobility (McDowell, 2003; Bolton and Houlihan, 2009).

We utilise ethnographic methods to explore the experiences of working class men in two occupations which can be defined as low skilled, where dirt and its dispersal form a key component of the job: street cleaners and refuse collectors. In the polarisation of 'men's work' and 'women's work', these conform to gendered constructions of 'masculine jobs', that is: work which is seen as both 'heavy' (Soni-Sinha and Yates, 2013) and involving direct contact with physical dirt (Ashforth and Kreiner, 1999). Specifically, we draw upon an orientation to gender as 
Masculinity and Class

an active construction (Connell, 1995; 2000), practised in different contexts and interactions (Martin, 2003; 2004; Connell, 2000) and on conceptualisations of class as a 'social space' of relations, positions, dispositions and meanings (Skeggs, 1997; 2004). Accordingly, this paper is concerned with how gender is mobilised - drawn upon, acted out, resisted and undermined - in the context of dirty work, and how gender and class in particular may intersect within this occupational field. We find that class subordination is redeemed and elevated by adherence to traditional forms of masculinity where practising dominant gender grants workers a sense of enhanced self-regard. Self-enhancement also take place through selective social comparison (Ashforth and Kreiner, 1999; 2014) whereby individuals enhance self-esteem and maintain a valued identity by positioning themselves against others thought to be worse off. Social comparison is particularly important in the context of dirty work i.e. where individuals might experience identity threat (Sedikides and Gregg, 2008). Devaluation is further resisted by participants' attachment to images, experiences and practices of a 'preferred' past where nostalgic narratives are exploited by participants as a form of a more critical engagement with the present. We argue that masculinity is displayed in a particular way as a result of the shared sense and experience of subordination and vulnerability, rather than being rooted in a separate sphere of ontologically demarcated masculine power. As an extension of this point, we highlight the paradoxical character of nostalgic appeals to working class masculinity and community - serving at once as a basis for men's resistance to status devaluation whilst simultaneously reinforcing their subjective entrapment within subjugated forms of employment. Further, we suggest that combining social comparison with intersectionality can potentially highlight how categories of difference are mobilised in response to varied and unequally valued social positionalities.

\section{Masculinity and the Working Class Context}

Understanding masculinity as both socially constructed and relational involves looking at how masculinities are defined and maintained in different cultural contexts, and how other 
Masculinity and Class

categories of difference such as race and class might intersect. As Connell $(1995 ; 2000)$ notes, masculinities are sustained through collective social practices that take place in a range of institutions, both constraining and facilitating social action by embodied agents (Martin, 2004). These situated practices and embodied performances of gender, grounded in history and precedent, entail opportunities and constraints and a 'plethora of meanings and expectations, actions/behaviours, resources, identities and discourses' (Martin, 2003: 344). Martin draws attention to the 'twin processes' of gendered practice, as a 'class of activities' available 'culturally, socially, narratively, discursively, physically' (Martin, 2003: 354) to men and women in specific situations, and the practising of gender that entails individual enactments and bodily performances. This captures the notion that, as West and Zimmerman (2002) also maintain, gender performances take place in particular institutional contexts so that institutions, as purveyors of gendered narratives (Ashcraft, 2006), as well as individuals, are implicated in appropriate (or inappropriate) gender enactments. Institutions accordingly provide a 'repertoire of practices' (Martin, 2003) concerning what it means to perform a particular gender position.

As McDowell (2003) points out, social categories such as class, race and ethnicity are also major factors in the social construction of masculinity, interacting with gender to produce varied and unequally valued positionalities. This highlights the relational processes involved and the complex and often contradictory ways in which categories may intersect. An intersectional approach directs attention to how multiple and interlocking identities engender experiences within specific, contextually-based relations of power and how individuals engage in or disengage from these processes (Shields, 2008; Holvivo, 2010). This demonstrates both a fluidity and fixity of normative constructions of difference in that gendered and classed practices are partly constituted through enduring social relations of power. This was reflected in early work on masculinity and class which highlighted the 'injurious' character of class relations (Sennett and Cobb, 1972). Such analyses highlight how work is valued for the avoidance of unemployment, and 
Masculinity and Class

for the effort, strength and physical skill demanded (Willis, 1977; Tolson, 1977) reflective of a pragmatic approach and a 'practical consciousness' (Giddens, 1979) in working men's lives. As de Certeau (1988) and Giddens (1979) have each argued, by situating their lives in relation to their constraining circumstances, working class men develop 'the capacity to go on' and to create what Charlesworth (2000) describes as identities of value - identities respected by others.

More recent work has highlighted how, in a similar vein, working class men draw on hard work, honesty, self-discipline and capacities for physical endurance in their struggles for recognition (Simpson et al, 2014; Thiel, 2007). These struggles have been set in the context of a contemporary class positioning which, against the background of dominant values of personal fulfilment and progression, frame working class subjectivity in detrimental terms - as lacking in value and undeserving of respect (Sayer, 2005; Skeggs, 1997; 2004). As Sayer (2005) argues, class is not just a location in a particular field or social space but is also deeply embodied, permeating experiences, emotions and sense of self. Devaluation in the workplace and acts of 'downward discrimination' from those with power to implement disciplinary processes can accordingly be keenly felt (Dolan 2007). In this respect, strong occupational cultures based on the maintenance of the manual/non-manual divide, a primacy attached to breadwinner roles, and a worldly realism that accords with an instrumental approach to work comprise, in Willis's (1977) terms, a potentially positive source of class identity.

In his discussion of the construction of valued identities, Collinson demonstrates how men on the 'shop floor' invest in key discursive practices of both resistance and acquiescence to deny processes of occupational subjugation and to secure a 'positive, productive meaningful world' for themselves (Collinson, 1992: 39). Men exploit their dominant gender position through displays of independence and self- containment to enhance their self-value, while still retaining sensitivity 
Masculinity and Class

and susceptibility to the demands and expectations imposed on them by others. Drawing on a study of construction workers, Thiel (2007) shows how potential stigma from class can be mitigated through adherence to traditional class-based masculinity. Taken together, this work demonstrates how the 'lived reality' (Skeggs, 1997) of working class experience must be set in the context of a changing landscape characterised by an increasingly insecure labour market positioning and by a contemporary moral framework, based on middle class sensibilities of selfadvancement, that affords little respect to those involved in less skilled work.

\section{Dirt, Class and Masculinity}

These struggles and challenges are particularly pertinent for those individuals undertaking 'dirty work' (e.g. work involving the handling and disposal of others' waste) where stigma attached to dirt can reinforce class-based devaluation. As Douglas (1966) argued, our ideas of dirt, as impurity are an expression of symbolic systems that "offends against order" (Douglas, 1966, p.45) so that boundaries are constructed between the orderly and the disorderly, substantiating the threat of contamination if these boundaries are transgressed.

As Sayer (2005) suggests, people experience class in relation to others via 'moral and immoral' sentiments based on how some groups are assessed. Meanings attached to dirt are therefore relevant to understanding its relation to class and social position. In this respect, avoidance rules dictate that work which deals with polluting, physical dirt is commonly carried out by members of 'lower classes', separated socially from other groups (Dick, 2005; Skeggs, 2004; Roberts, 2001). Proximity to dirt accordingly constitutes a divide between those who can withdraw from whatever bears traces of contamination and impurity and those who have little choice in the jobs they do. Further, as Hughes's (1958) seminal work demonstrates, social position is implicated in how dirty work is managed and experienced. Thus, dirty work undertaken by those of a higher standing (e.g. bodily care performed by doctors) can be 'integrated into the whole' so that contact with dirt (e.g. direct exposure to bodily effluence) can be mitigated by 
Masculinity and Class

other, socially privileged aspects of identity. Those further down the hierarchy may have fewer status shields to manage tainted effects.

For van Vuuren (2012) individuals in low status 'dirty work' occupations are confronted with 'an ungrateful trade-off': they are mandated to do these jobs, but stigmatized when doing them. Perceptions of stigmatization have been found to affect individual and collective esteem (Paterson et al, 2012; Crocker et al, 1989) and evaluations of one's social identity. The process of ordering and/or classifying determines the special relevance of social class and occupational status for self-esteem which rests in the comparison of one's position with that of other people. In this respect, through selective social comparison, those in dirty work occupations have been found to place weight on social referents that affirm the workers' value (Ashforth and Kreiner, 1999; 2014; Stacey, 2011). By comparing themselves favourably to more disadvantaged social groups, individuals seek to protect themselves from devaluation (Paterson et al, 2012).

Further associations can be drawn between dirt and gender. As Tracy and Scott (2006) point out, gender is implicitly rather than explicitly recognised in the literature on dirty work perhaps because different types of dirty work often conform to traditional notions of femininity and masculinity where gender, as in the gender segregated work of refuse collection and street cleaning, is normalised and hence concealed. Thus, jobs that entail some forms of physical taint (i.e. where there is direct involvement with dirt or danger) and where manual labour is involved are commonly, though not exclusively, associated with working class men (Ackroyd and Crowdy, 2000; Ashforth and Kriener, 1999; Tracy and Scott, 2006). While recognising that women are also employed in physically tainted work (e.g. jobs involving bodily care), gendered practices tend to be otherwise dominated by notions of traditional masculinity that pertain to the development of 
Masculinity and Class

endurance in the face of aversion; to occupational cultures based on an 'us' and 'them' mentality (Ashforth and Kreiner, 1999); and to a strong differentiation from women (Ackroyd and Crowdy, 1990). Thus, as Tracy and Scott (2006) found, firefighters mobilise traditional discourses of masculine heterosexuality to reframe their work in preferred terms. Ackroyd and Crowdy (1990) highlight how slaughtermen develop a distinctive occupational culture based on aggressive realism where debris from blood and gore was often worn on clothing as a source of masculine pride. Men accordingly mobilise masculine distinctiveness based upon a special ability to endure the 'tainted' aspects of the job. This highlights how, as Dick's (2005) suggests, studying dirty workers and how they deal with taint can provide an opportunity to examine the dynamics that exist between occupations and the broader social context, and how the moral boundaries and margins of the social order are both contested and maintained.

Against this background, this paper focuses on how gender can be mobilised in physically tainted work and how it can recapture value in a context of potential stigmatisation and subordination attached to occupation and class. Our broad research question is as follows: How do working class men practise gender in the context of dirty work, and how do other categories of difference such as class support and/or intercede with gendered practices of 'dirty workers'?

\section{Context}

The two occupations we consider, refuse collection and street cleaning, are male dominated and conform to the ONS (2010) classification of 'elementary' cleaning occupations i.e. as requiring little or no formal or on the job training characteristic, as Atkinson (2010) suggests, of low-skilled manual working class jobs. Both occupations have been subject to considerable change over the past few decades. Key to the transformation of public sector service delivery was the Local Government Act 1988 which obliged local authorities to expose blue collar services to 
Masculinity and Class

competitive tendering, leading to the contracting out of such work to the private sector. A recent report shows that the sector employs around 128,000 people with only 22,000 directly employed by local authorities (Aulakh and Thorpe 2011: 5). The ongoing neo-liberal agenda has led to an overall fall in expenditures on such services (Gomez-Libo and Szymanski, 2001), work intensification, widespread de-unionisation, less secure employment conditions and downward pressure on wages. In their attempts to minimise costs and maximise returns, private contractors now routinely draw on agency workers who receive lower wages and have fewer employment rights than permanent employees (Aguiar and Herod, 2006).

Despite a shared occupational positioning, work practices vary significantly between the two occupations. Refuse collection, normally covering 1,600 houses a day, involves two key elements: 'pullers' collect all of the black refuse sacks or recycling bins from front gardens and alley ways and place them in piles by the side of the road ('black bag' rubbish and recyclable waste are collected by separate teams). The 'loaders' then throw the bags or recyclable waste into trucks which are usually emptied twice a day. The trucks are driven by 'bankers' - skilled drivers who normally head the team and who must be able to reverse around tight corners and manoeuvre in narrow suburban streets. Team-based work practices engender a strong occupational culture based on camaraderie and a valued and pleasurable humour ("having a crack") providing defence against assaults on identity (from the public; from the often grim character of the work). Such resources are not available to street cleaners who typically work on their own and who appear particularly vulnerable to negative effects. Their day starts early $(6.30 \mathrm{am})$ so that streets can be swept before commuters arrive. First swept are the streets that are cleaned daily, then there is a rota for streets that are cleaned weekly.

Participants comprised almost exclusively white working class men - a dominant category within our chosen occupational groups, and one which has arguably been experiencing particular 
Masculinity and Class

disadvantage as a result of de-industrialisation (Charlesworth, 2000; Thiel, 2007). The research project took place in West London, which has been particularly affected by these changes. Major industrial closures between 1970 and 1990 included employers such as Watney Mann and Truman, Hoover, Ford, British Leyland, Whitefriars and Westland helicopters - all of which had a share of their workforce based in that area. Our choice of sample was directly informed by our engagement with the effects of such longer-term transition, with a particular focus on experiences, for example, of deindustrialisation and the increased competition for jobs (Alcock et al, 2003), as well as the negative attitudes that might be triggered by the association with dirt and low social standing of the occupational groups we considered.

\section{Method}

In recent years, the refuse industry has been shaped by a wider push to extend the role of private companies which, as suggested above, has resulted in competitive tendering or contracting out and has led to a decline in pay and conditions, affecting, in particular, sickness, holiday pay and pensions (Rowbotham, 2006). In addition, since the recession, key employers have increasingly been contracting their workforce on a temporary basis. In this study, the majority of men were permanent employees of the contractor, with the remainder (both migrant and indigenous workers) agency staff on temporary contracts. Participants were aged between 18 and 64, though the street cleaners' age range was skewed towards the older category with most in the 40-55 age group. Contact was made through telephone and email with councils and contractors in and around London. One council in Greater London and two contractors agreed to take part in the study. Once permission for access had been granted, typically a date was set where the research team (one man and one woman) would come on-site, work alongside the participants where appropriate, and conduct the interviews 'on the job'. While there was a concern that this 'top-down' method might lead to a lack of disclosure on the part of participants, 
Masculinity and Class

the presence of the research team generated considerable interest and amusement. The break the interview afforded in the routine of the day was often a welcome one.

The research drew on a two-tiered ethnographic approach of participant and nonparticipant observation fieldwork and semi-structured interviews. As Tyler (2012) argues, ethnographic methods are particularly well suited to bringing into focus how dirty work and gender may be enacted and experienced. The observational fieldwork involved two researchers spending five days working with four teams of refuse collectors 'on the dust': taking full part in the day-to-day tasks and activities. The researchers (for a further five days in total) then accompanied the street cleaners on their daily rounds, observing and talking to men about their work routines. Ethnographic observation not only allowed us to see some of the habitual and mundane practices that might otherwise have gone unexplored, but helped to reverse the social dynamic between subject and researcher - placing our participants (through possession of knowledge and expertise) in a contextual position of greater authority and power. Furthermore, working and interacting alongside the participants within their familiar context enabled researchers to experience otherwise inaccessible sensory impressions (such as the feel and smell of the work) as well as to actively engage in the everyday conversation which is so strongly linked to time and the passing of the day. Field notes were taken and written up after each working day.

Twenty one semi-structured interviews were conducted (13 street cleaners, 8 refuse collectors). These were fully recorded (using an unobtrusive device that was clipped to the participants' clothing, allowing freedom of movement) and took place in situ, typically on the street, and in collection trucks. In terms of the latter, the researchers found that an optimal way of working (one which minimised the degree of disruption to the daily routines of participants) 
Masculinity and Class

involved one researcher undertaking the interview while the other worked alongside the crew to replace the 'lost body' on the street.

At interview, researchers focused on key themes relating to life and work history; opportunities/job choice; family experience; work practices (e.g. a typical working day), enjoyable/challenging aspects of the job; and plans/aspirations. Interviews were tape-recorded and transcribed in full. Thematic analysis was undertaken to identify key themes or "patterns of experience" (Aronson, 1994) which then formed the basis for further more detailed analysis. Data were collected under each theme and subthemes based around "conversation topics, vocabulary, recurring activities, meanings, feelings" (Taylor \& Bogdan, 1984, p. 131). For example, the theme 'traditional masculinity' which emerged from our analysis was then broken down, informed by the data, into sub themes of physicality, endurance and instrumentality (elaborated further below).

Researcher engagement and reflexivity were a central concern. Such reflexive engagement took as its starting point an acknowledgement that occupational distance and gender difference, together with attendant power dynamics, are likely to have a significant influence over data collection and analysis. Through 'active listening' and an acute awareness of the potential influence of our own privileged occupational position, we sought to give a sympathetic voice to men's experiences where, in a more general context, male working class voices are rarely heard. Here, we sought what Charlesworth has referred to as a form of engaged committed interaction in which one 'helps the other to articulate the pieces that have contributed to the totality of their experience' (Charlesworth, 2000: 144). Similarly, while gender differences may serve to introduce a constraint on men in terms of willingness to disclose innermost thoughts 
Masculinity and Class

and feelings (Simpson, 2009), other feminist work (e.g. Evans, 2002) suggests women can under certain conditions offer a 'truer understanding' of men and masculinity on the grounds that their marginalised position means they are less imprisoned within established epistemological frameworks. In fact, for both the male and the female researcher, there was an ease in terms of shared reflections and disclosures in the interview situation. Furthermore, the active participative phase of the field work helped to break down barriers (occupational, gender) as men appreciated the willingness of the researchers to 'roll up their sleeves' and give the work a go - and as their participation afforded men an opportunity to display a higher order level of competence and expertise.

Our findings below present key themes that capture different facets of how gender, class and occupation intersect in men's experiences of dirty work. These inform our core argument that masculinity is practised in particular ways partly as an expression of the consequences of class positioning and attendant experiences of subjugation. Such experiences further relate to a dynamic nexus between class subordination and masculinity; status devaluation and worker's attempts to resist this; and the mobilisation of nostalgia and esteem-enhancing modes of social comparison as at once resources for worker agency and subjective 'anchors' to enduring structures of domination and disadvantage.

\section{Class Subordination and Masculinity}

Once we arrived at the start of the route we all jumped out, and Dave explained to me how this crew works, "In the yard there are two types of black bag teams and two types of recycling teams, those who run and those who don't. We run!" The fact that some teams can do their route while running engenders a sense of pride, and is a source of differentiation from other crews. I was tempted to think Dave was bragging. I was wrong. They ran for the whole route. While those on 
Masculinity and Class

the black bags get pride from the weights they have to lift throughout the day, therefore seeing those on recycling as a 'weaker' alternative (the refuse is lighter and cleaner), those who do the work 'on the jog' get similar satisfaction from bodily fitness and fortitude. 'Toughness' is consequently restored". (Field notes, refuse collection)

Refuse collectors and street cleaners clearly identified themselves as 'working class' and designated their jobs as such. This self-identification reflected a conscious awareness of both their objective circumstances and subjective experiences. Most participants left school between the age of 15-17, typically not continuing their education and having a succession of low wage jobs. Many resided in the same areas within which they were born. Participants were aware of their objective class positions which influenced, more subjectively, their sense of 'selves' as well as justifications for important life choices. Class for them was at once both a source of pride and of profound vulnerability.

...it is a working class job, it's not to be vilified, some people will talk in those terms but there should be acceptance of different classes and not looked down upon (refuse collector).

I am working class and there's nothing wrong with working class, there's nothing to be ashamed of being working class, it's very hard to change a class... There's working class people doing what is traditionally known as working class jobs, and they should be, you know, proud to do that... we don't want everybody being planners, accountants, you know. We can't all be teachers, we need people to do other jobs don't we? They play a role (refuse collector).

The quotes above registered the complex relationships between pride and self-respect with the work of street cleaners and refuse collectors positioned detrimentally against more middle class occupations, understood to be of less value than 'planners' and 'accountants'. Here, participants 
Masculinity and Class

drew on traditional notions of masculinity to manage and resist class-related subordination. As the field notes above attest, participants typically emphasized their ability to perform physically demanding tasks, placing value on physical strength and corporeal resilience. As Tracy and Scott (2006) suggest, physically tainted work lends itself to conventional displays of masculinity from the endurance, effort and fortitude involved. In this context, as has been documented elsewhere, men activated norms and behaviours around bodily capabilities that helped to regain and maintain their sense of worth and hence resist the low status attached to class and occupational positions (Ashforth and Kreiner, 1999; Willis, 1977; McDowell, 2003; Charlesworth, 2000).

"It's a tough job but we chose it... I didn't leave [school] with an education, but I thought I got a head like anyone else, eyes like anyone else, a brain like anyone else so I just did it, learned on the job". (Street cleaner)

Drawing on traditional meanings of resilience and discipline, and supported by attitudes of practicality (highlighted in the above quote), men demonstrated strong adherence to normative discourses which stress the importance of having and retaining a job. This places emphasis on 'graft' namely, working hard, 'sticking at it', irrespective of the perceived status or 'desirability' of such work:

"My thing is as long as I've got a job at the end of the day that's it, that's the way I see it. I mean I've even worked at Burger King, McDonalds for a week or so, just that I'm working until another job started and I've always worked". (Street cleaner)

The underlying rationale for work was mainly the ability to earn a wage, however minimal (most were on minimum wage, taking home about $f 800$ per month at the time of the study) reflecting principles of necessity and a 'continuing functionality' (Thiel, 2007) in working class lives. Self-esteem was established through the emphasis on continuous employment, independence, self-reliance and breadwinner roles. The significance of the latter is captured in the quote below: 
"And we got married, started having children. And to me in them days, I said, "No, I'll work, you stay at home". I mean that was the rules in them days, you know what I mean, it was... now times has changed, where the woman can go out to work as well. But to me, I always thought, no, I think a woman should have more time to herself, the worries should be for the bloke, not for the woman". (Street cleaner)

Most men adhered to traditional gender roles, claiming financial responsibility for their families - despite the challenges of doing so on a low wage (a common source of discontent). However, only one third of wives and partners of participants could be described as non-working (i.e. fully dependent on their partner's wage) with the remainder in a variety of full time or part time jobs. Despite this, as the streetcleaner above illustrates, some men still adhered to traditional notions of 'protecting' wives and partners from the demands and "worries" of work.

Taken together, male 'dirty workers' characteristically practised a traditional form of working class masculinity that affords meaning to what is considered to be undesirable work. Here, primacy is attached to physicality, effort and endurance in performing strenuous tasks, retaining employment and giving support to families - themes that are consistent with many previous studies of working class men (e.g. Willis, 1977; Connell, 2000; 2005; Charlesworth, 2000; Sennett and Cobb, 1972; Sayer, 2005). In a development of this theme, Sayer (2005) suggests that gender dominance provides working class men with a form of pride that they often 'misread' in class terms and attribute to their class position (Sayer, 2005). This reading (or misreading) leads to the intensification of men's attachment to traditional forms of masculinity in their attempts to resist class devaluation: a paradoxical double-bind arising from the intersection of gender and class. The intersection with occupation further compounds this tendency. Dirty work that calls on men's supposedly 'unique' capacities for strength and endurance allows a platform for working class men to practise a recognized and traditional form of gender, enabling them to recover value 
Masculinity and Class

that might be threatened through class subordination, whilst simultaneously reinforcing their entrapment within such 'traditional' subjugated occupational fields.

\section{Social Comparison}

The banter kicked off from the start with Phil taking delight in my difficulty in swinging almost every bag into the truck. "The difference between you and me" he asserted "is that you make this job look difficult" and he was right, I am sure I did. "This job ain't difficult but it is tough for the likes of you. You need to think of it like chess... always think of the next move ahead, where are the bags? Where do I need to go?" Phil placed a lot of pride in his ability to lift three or even four bags in one hand, relating to his experiences as a power-lifter in the past. Pride was also placed on this ability to throw the "right bag" into the truck from fifteen or twenty meters away. When I asked him to show me, he rose successfully to the challenge. (Field notes, refuse collection)

As Ashforth and Kreiner (1999; 2014) suggest, selective social comparison which relies on the positioning of self against others thought to be worse off, can help individuals draw esteemenhancing inferences in a context of identity threat (in the field notes above a refuse collector positioned his abilities favourably against the ineptitude of one of the researchers). These stratifying practices may be particularly pertinent where perceptions of taint place individuals at the bottom of the institutional hierarchy, as in forms of dirty work. From our study, these practices were based largely on 'superior' embodied capacities compared with women and/or with different 'types' of workers. In terms of the former, while gender was rarely raised as an issue, perhaps reflecting the normalisation of masculinity within this gender segregated occupational context, the presence of a female researcher triggered several gender comparisons. Typically, these were variations on the theme that women were unequal to the work. As one refuse collector commented: 
Masculinity and Class

"... they (women) can't do it, it's too dirty for them and they say they want equality why won't they come and do this job? ... They won't come and physically do this because they reckon it's too hard ..." (refuse collector).

Hierarchies were also drawn on the basis of job-related factors such as contractual status (agency/permanent); on migrant status; on the employed/unemployed distinction; on the manual/non-manual category of work. Agency workers were positioned as deficient (lazy, less committed, less disciplined) by permanent employees ("you wouldn't throw water on them if they were on fire because they are that useless"). Migrant workers were seen as "hard grafters" and as opportunistic - undercutting trade union power and creating unwelcome competition for jobs. Those out of work and on benefits were seen as lazy and workshy, triggering feelings of injustice due to their shared social and economic space with low paid workers ("it's just that some people just don't want to work, you can either take $f 65$ a week on the dole or you could earn a bad wage doing this job".) Other groups, particularly white collar, were similarly positioned as incapable of withstanding the rigours of the job:

Not everyone is able to actually do road sweeping because it's a bit more difficult than they think... Physically, physically it's very demanding. Also, I think nowadays it's progressed where you must be - and it's no disrespect to anyone who can't - but you must be able to read a map... We've had businessmen that have fallen out of work, very well educated... and decided that if they can't get another job they would just go and be a road sweeper, and they come here and I'll take them out and I'll explain to them 'This is what we have to do'. And more likely than not they will last about two hours because they're unable to do it. Like I say, because physically they can't do it". (Refuse collector)

According to Charlesworth (2000) and Sayer (2005) the basis for working class pride differs significantly in its normative assumptions from a middle class understanding of what is of value with its focus on acquisitions of cultural capital (education, schooling) and autonomous careers 
Masculinity and Class

that carry authority over others. In the quote above, 'very well educated' is positioned in detrimental terms against the extreme physical rigours of the work ("physically they can't do it"), given extra emphasis in a two hour limit placed on the assumed capacity of a 'businessman' to endure the demands of the job. Normally valued middle class backgrounds and privileges are, in these spaces, diminished - carrying little worth in a context which demands embodied strength and fortitude.

Other comparisons were invoked in order to be rejected and undermined. With implicit reference to class position, lines of division emphasised by managers and office workers - based on the primacy attached to non-manual work in mental/manual distinction - were challenged as irrelevant. Here men sought to diminish difference by reinforcing the significance of mutual goals:

"Oh yeah, yeah, well some people once they get a suit and tie on and getting the manager, you know they think they're the bee's knees you know, but at the same token all the cogs in the wheel make the job go, flow round sort of thing, you know... they think they're the bee's knees and they're not, you know. And you know as far as I'm concerned everybody who works for the same company it's all part of a team and it's just that the individuals think you know they're beyond everyone else". (refuse collector)

As Connell (2000) notes, masculinities are typically hierarchically ordered. In the context of dirty work, an embodied masculinity based on hard work and endurance (Willis, 1977; Collinson, 2002), often associated with subordinated men (Connell, 2000), can be presented as taking cultural precedence over middle class gender constructions around disembodied rationality and control (Kerfoort and Knights, 1993; 1998). The latter however confers authority over others in the workplace - hierarchical differences that, as Dolan (2007) has shown, can be keenly felt (captured in "they think they're the bee's knees" that refers to managers' supposedly elevated self-perceptions). As Collinson (1992) has demonstrated, the sense of inequality and grievance on the part of manual workers are a direct consequence of their institutionalised inferiority, 
Masculinity and Class

embedded in the hierarchical relations between white collar and manual work. In seeking to escape negative judgement (e.g. based on dominant middle class values and sensibilities), social comparison can help establish alternative evaluation criteria and so reduce differential status effects. However, by elevating manual work and embodied capacities for hard work, endurance and commitment in comparison to others, men simultaneously reproduce the relations of power in which they are subordinate.

\section{Devaluation and Nostalgia}

Before we headed out, a heated exchange broke out between one of the street cleaners and management staff. The hierarchies that exist within the organisation were made clear: one of the gully workers had been put on a barrow but was left less than impressed by this temporary 'demotion'; "I'm not fucking gonna do it! I'm a driver. Where in my contract does it tell me to sweep?" His anger at the job he was given for the day was quashed by one of the office managers who bluntly retorted to take his complaint to the union. (Field notes, street cleaners)

In a manner which accords with Dolan's (2007) findings, participants in this study were acutely aware of the hierarchical structuring of social interactions and how these were manifest, in their view, in their unjust treatment and devaluation. Discontent with the present (current institutional arrangements and work practices such as casualization) led to nostalgic comparisons with a more 'favoured' past. Typically such comparisons were used as a platform for the expression of feelings of dislocation, in turn rooted in the long-term reduction of trade union power and greater competition for jobs from casually employed, migrant workers.

As the confrontation between a manager and an employee in the above extract shows, participants struggled with their subordinated status and the imperative to comply with what were often seen as unjust demands of management. Increased competition for jobs and 
Masculinity and Class

participants' relatively weak labour market positioning forced men to consent to unwelcome changes in work practices (an unexpected demotion in job role; the wearing of pagers that tracked progress on the streets). These experiences of subordination were reproduced through day to day encounters with members of the public. As one refuse collector commented, "They'll say, "Oh low life," you know, try to degrade you". Another referred to routine disparagement from peers:

Yeah, yeah, oh they say it, they talk about dustmen in the pub. You know, because obviously when I'm not at work I don't wear the uniform and I'm sitting there and, you know, "oh those stupid dustmen and this, they're all as thick as dog's do and all that", you know, "well fair enough mate, keep going, you know", I'm smarter than you are, you know... (refuse collector).

A refuse collector described how a woman "clicked her fingers" in a command for attention; another recalled how a car nudged his calf in an extreme demonstration of impatience and lack of regard. Concern that a confrontation may get out of hand ("getting verbal"), violating public service norms of politeness and so potentially jeopardising future employment, meant that anger and disagreement had to be contained:

"We're not supposed to take aerosols, we can't take televisions ... of course (the public) don't understand, when you say to them "look I can't take your TV", "I pay my f'ing rates: you should", "no we can't take it mate, you know". "I'm going to phone", "well go ahead phone up, see if I care", and I'm being very polite. You do have a tendency to want to get verbal with them but you can't because of the job". (Refuse collector)

Here, a desire for retaliation is 'reigned in' by the imperative to protect employment, replaced by a measured practicality ("we can't take it, mate"). This concern for job security was repeatedly voiced: 
Masculinity and Class

"They've got to make this 126 million cut. They can streamline us, there's no two ways about it, they can take one bloke off each lorry, I know they can do that ... somebody is going to be on the chopping block..." (Refuse collector)

Harsh economic realities - labour market conditions in which a worker is easily replaceable with a more compliant, possibly cheaper counterpart - set limits to practices of resistance. Yet, paradoxically, notions of class, tradition, position, value - with all the hierarchical divisions these entailed - figured prominently in narratives of loss when comparing the past to the present. Crucially, men inferred a past in which class and work were better aligned, in which working class voices were heard and their position respected, however begrudgingly, by employers. Comparisons with the past typically involved sentiments of loss and fatalism ("I'm that dying breed that's still represented, that's working class..."). These opened up possibilities, in Strangleman's (2007) terms, for a more critical engagement with the present as well as for concerns about the future:

"Yeah, a lot easier (in the past), a hell of a lot easier, you could leave one job, go straight onto the next one, start the next day. But now it's... well I've got three sons, I've got one son that works, one son out of the three and that's my youngest and he's $30 . .$. yeah, 30 now, l've got two older sons and they just can't find work, they can't find work...". (Street cleaner)

"It'd be hard to get on in life. Like my son, he's got his own little business, of building, but there's so many people doing it... Where ... hopes for the children nowadays, very slim, very slim. I feel sorry for the children, like these youths, like 17, 18 year olds, they leave school for what?". (Street cleaner)

Typically, attention to the presence and strength of trade unions formed a core part of a nostalgic narrative. Men frequently referred to the declining power of the unions, and their current 
Masculinity and Class

inability to reverse or effectively challenge change. The hidden sarcasm expressed by the manager in the episode described in the field notes above - where he suggested the worker "take his complaint to the union" - infers, somewhat mockingly, an option now foreclosed. The unlikelihood of union support and the precariousness of the workers' position underpin the need to accept the manager's directive: 'go take it to your union- you won't get anywhere, and you'll be easily replaced' is the unspoken sentiment. Typically such retrospectives triggered nostalgia for the "old days" of union power and worker solidarity:

"The union are supposed to be fighting ... they've been sort of less prone to use the strike weapon really. So they're generally, you know, less sort of powerful really as they used to be...". (Street cleaner)

"We don't see that many... we'll see the odd strikes here and there, but just don't seem to be as much power. 'Cause I remember in the old days, in the '80s, when the old miner's strike was on, I went down the old coast to see the old miners and all that, help them out and all that, and now it's, you know, a lot of people all come together then, now don't seem to get that anymore". (Street cleaner)

Participants' nostalgic narratives were accordingly shaped by a sense of loss and 'disagreement with the present' (Boym, 2001) as both an expression of attachment to the past and reservations about the future. The decrease in trade union power was also attributed to the presence of migrant workers, who were understood to be willing to work for lower wages and less aware of workers' rights:

"[When] immigrants come in as far as the union is concerned ... they're obviously prepared to work for lower wages, and I think that produces a problem for them (the Unions)". (Street cleaner). 
Masculinity and Class

"I mean some of them (migrant workers) they don't understand what rights they have, what they, you know, so they don't realise" . (Street cleaner)

The discussion of recent societal changes revealed the feeling of social dislocation ('we are a dying breed...') which was also connected to the presence of 'foreigners'. The figure of the 'foreigner' appeared in a variety of discourses, including those relating to job loss, community cohesion (and its breakdown), the absence of collective history, common language and shared values. The presence of foreigners again signalled irreversible changes - changes that were perceived by participants as a threat to their own identities.

"I mean there's a lot of foreigners round now. I don't mean that in a... [laughs] I mean when was round there everyone in the '60s, '70s everyone was English, you know everyone talked to each other, now you say hello to people, good morning to people and they just ignore it, just walk past you". (Street cleaner)

This sense of 'foreignness', set against notions of indigeneity, was less associated with ethnic or racial differences than with a perceived willingness to accept poor contractual conditions and a loss of community. Anxieties about migrant labour therefore expressed men's attempts to make sense of their own feelings of insecurity, loss and dislocation rather than a sublimated hostility towards 'others' based on a particular category of difference.

Taken together, these experiences illustrate how in the context of working class men doing dirty work, negative moral evaluations stemming from class position (Skeggs, 1997; 2004) and subjugating interactions associated with menial work can combine to place men in a subordinate subject positioning. This status is partly characterised by feelings of social dislocation, rooted in the decline in trade union power and in perceptions of threat from foreign workers. Subordinate status and devaluation can arguably be resisted by adherence to the image of the 
past. As Bonnett (2010) and Strangleman (1997; 2007) suggest, nostalgia concerning, for instance, the passing of an age of closer-knit communities and more traditional values can be read as a form of resistance - a strategic device that opens up possibilities for a more critical engagement with the present. Such ideas accord strongly with those of our group of workers who problematize their current circumstances and lament the loss of job availability and political power. Here a nostalgic past serves as a kind of 'yardstick' against which the present can be held to measure up or fall short. However, continual reference to 'anchors' in a working class past simultaneously serve to reinforce the men's entrapment within subjugated occupational fields, further consolidating class as a marker of (devalued) identity.

\section{Discussion and Conclusion}

Against a background of an 'invisibility' of class in recent gender and organization research (McDowell, 2003) and the increased vulnerability of low skilled men within the contemporary labour market (Nixon, 2009; Alcock et al, 2005; Gregg and Wadsworth, 2003), this paper set out to explore the investment of men involved in 'low level' occupations in particular gendered and class practices. Our study has contributed to an understanding of the complex and often contradictory ways in which the dynamics of practising gender and the interplay between categories of difference in the context of dirty work unfold. We have shown how men encounter relations of subordination embedded in their class position, the employment relationship and low job status; how ethnicity is implicated through meanings attached to migrant workers as a source of job competition; and how men respond to their positioning through appeals to working class masculinity and community. Further, we suggest that, rather than being located in a separate sphere of masculine dominance, masculinity is acted out in particular ways in response to and as an expression of these specific class and occupation based relations of power - relations which capture, additionally, the significance of ethnicity through understandings of 'foreignness', both as a source of job related insecurity and feelings of potential dislocation. 
Adherence to traditional displays of masculinity based on possession of physical strength and on values of effort and hard work can partially restore identities that are undermined by class as well as the dirty nature of the job. As other work has found (e.g. Willis, 1977; Ashforth and Kriener, 1999), a stress on physicality - on bodily capacities for hard work and endurance - is a form of resistance to devaluation. Further, men display instrumentality and practicality in their approach to work. In possible response to their 'institutionalised inferiority within structures of organizational power' (Collinson, 1992), men invest materially and symbolically in continuous employment and a regular wage as a means of economic subsistence (for self, for families) and as a positive marker of esteemed masculine self-reliance. Pride in continuous employment enables men to recover dignity in a context where dominant middle class sensibilities (e.g. around career progression) would position them as deficient. To this end, adherence to traditional displays of masculinity can be seen to form part of an oppositional strategy to the experience of class and occupation based subordination and devaluation.

Further, through social comparison, men in this study sought to resist subordination and create a positive identity. Social comparison is particularly important in the context of dirty work as a form of self-protection where individuals might experience a perceived threat to their selfesteem (Sedikides and Gregg, 2008). As a number of scholars have already shown (Ashforth and Kreiner, 1999; 2014; Stacey, 2011), selective social comparison boosts the positivity or diminishes the negativity of self-regard (Arkin, 1981; Miller and Slus, 1977; Sedikides and Gregg, 2008). Thus, streetcleaners and refuse collectors draw comparisons with the less valued identities of more vulnerable groups (women, temporary workers, migrant workers, the unemployed). Social comparison also involves dismissing those further up the hierarchy who might 'look down on' individuals concerned. Stacy (2011) found that care-workers positioned medical professionals as 
'out of touch' with the demands of day to day patient care. Equally, men in our study dismissed the hierarchical relations based on white collar versus manual work by highlighting the physical incompetence of white collar workers as well as by claiming similarity in terms of shared goals.

We observed how intensified competition for jobs and increased labour market insecurity have forced men to accept unwanted changes in work practices. Participants' disagreement with these changes found its clearest channels of expression in their discussion and comparisons with past perceptions and practices. The nostalgia permeating participants' accounts can be read as a form of resistance to unwelcome changes and, as such, a means for practical critical engagement with the present. Nostalgic sentiments also served to highlight participants' difficulties in parting with unfulfilled expectations concerning their work futures (i.e. life-time employment, secure skilled jobs, and family and community structures). As others have suggested (Bonnett, 2010; Boym, 2001; May, 2010), the experience of social dislocation and the perceived lack of fit within labour conditions have a profound bearing on the choice of practices and tactics used for selfproduction and self-representation. Retrospective reflection in some ways empowers men to express their concerns about the present and to resist current experiences of devaluation.

We can see from the above how, in a contemporary context characterised by the dominance of more highly valued middle class sensibilities, men develop reflexive narratives (based on embodied standard of prized masculinity; a bygone working class era; and the distinctive demands of dirty work) which can turn class into a valorised social category and a positive source of identity. Physical capacities of effort and endurance may have little value in a modern service economy, but they can be a source of (oppositional) personal power in dirty, manual work where, as we have seen in men's construction of the manual/non-manual divide, dominant middle class values and experiences are undermined. As Skegg's (1997) argues, adherence to established working class masculine values reflects constrained opportunity 
structures. Thus attachment to traditional notions of working class masculinity may afford a sense of personal power and self-worth in the context of dirty work whilst reinforcing 'entrapment' in subordinated forms of employment (Willis, 1977; Collinson, 1992). Street cleaners and refuse collectors may construct distinctions between manual and non-manual work and reify the former through attachment to values of hard, physical effort but they are subject, largely, to the latter's disciplinary power - with little autonomy in their working lives. As Willis (1977) has similarly argued, the articulation of masculinity and class through the celebration of manual capacities employed as an expression of class-based freedom and autonomy obscures their real weakness in the labour market and reinforces existing relations of power.

Through an intersectional approach, we have highlighted how feelings and experiences of vulnerability and dislocation as well as the responses to devaluation are not reducible to any one aspect of difference but are formed at the intersection of class, gender, ethnicity and occupation. Further, our study has allowed a focus on the neglected area of the ways in which potential privilege and disadvantage are co-constituted and how identities are formed at the intersection of 'multiple vectors' (Nash, 2008) and differential access to forms of power. Masculinity accordingly becomes inseparable from being working class which, in turn, becomes inseparable from indigeneity, 'foreignness' and 'what it takes to do this job well'. Further, in response to Nash's (2008) call for a greater focus on the ways in which identities based on both privilege and oppression are actively positioned, we show how social comparison is implicated within an intersectional perspective. This gives additional focus on how intersections are strategically deployed, highlighting how individuals draw on differences and similarities based on both advantage and disadvantage to manage the lived experience of intersecting identities. On a final note, therefore, we have also shown through our study the benefit of combining social comparison with intersectionality in order to create a narrative, not just of how connections 
Masculinity and Class

between, as example, gender, class, occupation and ethnicity are encountered and experienced but also how in agentic terms these intersections are mobilised and drawn upon in response to multi-faceted social positionings and diverse experiences of power.

\section{References}

Adib, A., and Guerrier, Y. (2003) The interlocking of gender with nationality, race, ethnicity and class: the narratives of women in hotel work. Gender, Work \& Organization, 10, 4, 413-432.

Ackroyd, S. and Crowdy, P. (1990) Can culture be changed? Working with raw material: the case of the English slaughterhouse workers. Personnel Review, 19, 5, 3-14.

Aguiar, L. and Herod, A. (2006) (Eds) The Dirty Work of Neoliberalism. Malden: Balckwell Publishing.

Alcock, P., Beatty, C., Fothergill, S., Macmillan, R., and Yeandle, S. (2003) Work to Welfare: How Men become Detached from the Labour Market. Cambridge: Cambridge University Press. Arkin, R.M. (1981) Self-presentation styles. In J.T.Tedeschi (Ed.) Impression Management Theory and Social Psychological Research (pp.331-333). New York: Academic Press.

Aronson, J. (1994) A pragmatic view of thematic analysis. The Qualitative Report, 2, Spring. Available at http://www.nova.edu/ssss/QR/Backlssues/QR2-1/aronson.html. [Accessed 25 November 2011].

Ashcraft, K. (2006) Back to work: Sights/Sites of difference in gender and organizational communication studies. In B. Dow \& J. Wood (Eds) The Sage Handbook of Gender and Communication (pp. 97-122). London: Sage.

Ashforth, B. and Kreiner, G. (1999) “How can you do it?" Dirty work and the challenge of constructing a positive identity. Academy of Management Review, 24, 3, 413-434.

Ashforth, B. and Kreiner, G. (2014) 'Dirty Work and Dirtier Work: Differences in Countering Physical, Social and Moral Stigma', Management and Organizational Behaviour, 10,1,81-108 
Masculinity and Class

Ashforth B, Kreiner G, Clark M and Fugate M (2007) Managerial tactics for countering occupational taint. Academy of Management Journal 50, 1, 149-174.

Atkinson, W. (2010) The myth of the reflexive worker: class and work histories in neo-liberal times. Work, Employment and Society. 24, 3, 413-420.

Atkinson, W., Roberts, R. and Savage, M. (2012) Class Inequality in Austerity Britain, Basingstoke: Palgrave MacMillan

Aulakh, S. and Thorpe, L. (2011) From Waste Management to Resource Recovery: A Developing Sector. Report to the Department for Business, Innovation and Skills, Ekogen. Available at: https://www.gov.uk/government/uploads/system/uploads/attachment data/file/31750/111088-from-waste-management-to-resource-recovery.pdf. [Accessed February 2015].

Bauman, Z. (1998) Work Consumerism and the New Poor. Buckingham: Open University Press Bauman, Z. (2000) Liquid Modernity. Cambridge: Polity Press.

Bolton, S. and Houlihan, M. (2009) Work Matters: Critical Reflections on Contemporary Work. Basingstoke: Palgrave Macmillan.

Bonnett, A. (2010) Left in the Past. New York: Continium.

Boym, S. (2001) The Future of Nostalgia. New York: Basic Books.

Brod, H. and M. Kaufman (Eds) (1994) Theorizing Masculinities. London: Sage.

Browne, I., and Misra, J. (2003) The intersection of gender and race in the labor market. Annual Review of Sociology, 29, 487-513.

Collinson, D. (1992) Managing the Shopfloor. Berlin; New York: De Gruyter.

Collinson, D. and Hearn, J. (1994) Naming men as men: implications for work, organization and management. Gender, Work and Organization, 1, 1, 2-22.

Connell, R. (1983) Which Way is Up? London: Allen and Unwin.

Connell, R. (1995) Masculinities. Berkeley: University of California Press.

Connell, R. (2000) The Men and the Boys. Cambridge: Polity Press. 
Masculinity and Class

Charlesworth, S. (2000) A Phenomenology of Working Class Experience. Cambridge: Cambridge University Press.

Crocker, J. and Major, B. (1989) Social stigma and self-esteem: The self-protective properties of stigma. Psychological Review, 96, 4, 608-630.

de Certeau, M. (1988) The Practice of Everyday Life. London: University of California Press.

Dick, P. (2005) Dirty work designations: how police officers account for their use of coercive force. Human Relations, 58, 11, 1363-1390.

Dolan, A. (2007) 'Good luck to them if they can get it': exploring working class men's understandings and experiences of income inequality and material standards. Sociology of Health and IIIness, 29, 5, 711-729.

Douglas, M. (1966) Purity and Danger: An Analysis of Concepts of Pollution and Taboo. London: Routledge.

Evans, J. (2002) Cautious caregivers: gender stereotypes and the sexualization of men nurses' touch. Journal of Advanced Nursing, 40, 4, 441-448.

Frazer, N. and Honneth, A. (2003) Redistribution or Recognition. New York: Verso.

Giddens, A. (1991) Modernity and Self-Identity: Self and Society in the Late Modern Age. Cambridge: Polity.

Giddens, A. (1979) Central Problems in Social Theory. London: Macmillan.

Gomez-Lobo, A. and Szymanski, S. (2001) A law of large numbers: bidding and compulsive competitive tendering for refuse collection contracts. Review of Industrial Organization, 18, 105113.

Gregg, P. and Wadsworth, J. (2003) Labour market prospects of less skilled workers over the recovery. In R. Dickens, P. Gregg and J. Wadsworth (Eds) The Labour Market Under New Labour: The State of Working Britain (pp. 86-98). Basingstoke: Palgrave Macmillan. Holvino, E (2010) Intersections: the simultaneity of race, gender and class in organization studies. Gender, Work and Organization, 17, 3, 248-277. 
Masculinity and Class

Hughes, E. (1958) Men and Their Work. Glencoe IL: Free Press.

Kaufman, M. (1999) Men, Feminism and Men's Contradictory Experiences of Power. In J. Kuypers (Ed) Men and Power (pp. 59-83). Amherst, NY: Prometheus Books.

Kerfoot, D. and Knights, D. (1993) Management masculinity and manipulation: from paternalism to corporate strategy in financial services in Britain. Journal of Management Studies, 30, 4, 659677.

Kerfoot, D. and Knights, D. (1998) Managing masculinity in contemporary organizational life: a man(agerial) project. Organization, 5, 1, 7-26.

Kimmel, M. (1993) What do men want? Harvard Business Review, November/December, 50-63 LFS (2010) Labour Force Survey, London.

Martin, P. Y. (2003) "Said and Done" versus "Saying and Doing": Gendering Practices, Practicing Gender at Work. Gender and Society, 17, 3, 342-366.

Martin, P. Y. (2004) Gender as social institution. Social Forces, 82, 4, 1249-1273.

May, V. (2011) Self, belonging and social change. Sociology, 45, 33, 63-378.

McCall, L. (2001) Complex inequality: Gender, class, and race in the new economy. New York: Routledge.

McCall, L. (2005) The complexity of intersectionality. Signs, 30, 3, 1771-1800.

McDowell, L. (2003) Redundant Masculinities: Employment Change and White Working Class Youth. Oxford: Blackwell.

Nash, J. C. (2008) Re-thinking intersectionality. Feminist Review, 89, 1, 1-15.

Nixon, D. (2009) 'I can't put a smiley face on': Working class masculinity, emotional labour and service work in the 'new economy.' Gender, Work and Organization, 16, 3, 302-322

ONS (2010) Office of National Statistics, London.

Paterson, L., McKenzie, K. and Lindsay, B. (2012) Stigma, social comparison and self-esteem in adults with an intellectual disability. Journal of Applied Research in Intellectual Disabilities, 25, 2, 166-176. 
Masculinity and Class

Reay, D. (1998) Rethinking social class: qualitative perspectives on class and gender. Sociology, $32,2,259-275$.

Roberts, K. (2001) Class in Modern Britain. Basingstoke: Palgrave.

Rowbotham, S. (2006). Cleaners' organizing in Britain from the 1970s: A personal account. Antipode, 38, 3, 608-625.

Sayer, A. (2005) The Moral Significance of Class. Cambridge: Cambridge University Press. Sedikides, C., and Gregg, A. P. (2008) Self-enhancement: food for thought. Perspectives on Psychological Science, 3, 2, 102-116.

Sennett R. and Cobb, J. (1972) The Hidden Injuries of Class. Cambridge University Press.

Shields, S. (2008) Gender: an intersectionality perspective. Sex Roles, 59, 301-31.

Simpson, R. (2009) Men in Caring Occupations: Doing Gender Differently. New York: Palgrave Macmillan.

Simpson, R., Hughes, J., Slutskaya, N., and Balta, M. (2014) Sacrifice and distinction in dirty work: men's construction of meaning in the butcher trade. Work, Employment \& Society, 28, 5, 754-770. Skeggs, B. (1997) Formations of Class and Gender. London: Sage.

Skeggs, B. (2004) Class, Self and Culture. London: Routledge.

Soni-Sinha, U. and Yates, C. (2013) 'Dirty work?' Gender, race and the union in industrial cleaning. Gender, Work and Organization, 20, 6, 737-751.

Stacey, C. (2011) The Caring self: The Work Experiences of Home Care Aides. Ithaca, NY: ILR Press Stranglemam, T. (1999) The nostalgia of organisations and the organisation of nostalgia: Past and present in the contemporary railway industry. Sociology, 33, 4, 725-746.

Stranglemam, T. (2007) The nostalgia for permanence at work? The end of work and its commentators. The Sociological Review, 55, 1, 81-103.

Silva, J. (2013) Coming Up Short: Working-Class Adulthood in an Age of Uncertainty. New York: Oxford University Press. 
Masculinity and Class

Thiel, D. (2007) Class in construction: London building workers, dirty work and physical cultures, The British Journal of Sociology, 58, 2, 227-251.

Taylor, S. and Bogdan, R. (1984) Introduction to qualitative research methods: the search for meanings. New York: Wiley.

Tolson, A. (1977) The Limits of Masculinity. London: Tavistock.

Tracy, S. and Scott, C. (2006) 'Sexuality, Masculinity and Taint Management among Firefighters and Correctional Officers: Getting Down and Dirty with "America's Heroes" and the "Scum of Law Enforcement."Management Communication Quarterly, 20, 1, 6-38.

Tyler, M. (2012) 'Glamour Girls, Macho Men and Everything in between: Un/going Gender and Dirty Work in Soho's Sex Shops.' in R. Simpson, N. Slutskaya, P. Lewis and H. Hopfl (Eds) Dirty Work: Concepts and Identities (pp.65-90). New York: Palgrave Macmillan.

Vuuren, M. van, Teurlings, J., and Bohlmeijer, E. T. (2012) Shared fate and social comparison: Identity work in the context of a stigmatized occupation. Journal of Management \& Organization, $18,02,263-280$.

West, C. and Zimmerman, D. (2002) Doing gender. In S. Fensternmaker and C. West (Eds) Doing Gender, Doing Difference (pp.55-80). New York: Routledge.

Whitehead, S. (2004) Man: the invisible gendered subject. In S. Whitehead and F. Barrett (Eds) The Masculinities Reader (pp. 351-368). Cambridge: Polity Press.

Willis, P. (1977) Learning to Labour: How Working Class Kids get Working Class Jobs. London: Hutchinson. 